\title{
Henoch Schönlein Purpura- A Small Vessel Vasculitis: Case Report
}

\author{
Zubin A. Mahajan*, Sameera R. Mehta**, Raman Singh* \\ ${ }^{*}$ M.B.B.S., Bharati Vidyapeeth University Medical College, Pune, Maharashtra, India \\ ** Junior Resident, Department of Pathology, Smt. Kashibai Navale Medical College \& General Hospital, Pune, Maharashtra, India \\ DOI: 10.29322/IJSRP.10.10.2020.p10609 \\ http://dx.doi.org/10.29322/IJSRP.10.10.2020.p10609
}

\begin{abstract}
Henoch-Schönlein purpura (HSP) is an acute IgA-mediated multisystem disorder, characterized by the involvement of vessels of the skin, gastrointestinal tract, kidneys, joints, and rarely the lungs and central nervous system. The annual incidence varies geographically from 6.2 to 70.3 per 100,000 population in the pediatric group with a male predominance (Male: Female $=1.2: 1.0$ ). The triggers for HSP are widespread ranging from basic allergens such as insect bites to infections with Epstein Barr virus, adenoviruses, Mycoplasma, Legionella, even vaccines such as typhoid, measles, yellow fever and medications such as beta- lactam antibiotics, erythromycin, quinine or quinidine. The pathogenesis is believed to include a dysregulated immune response, that results in a pro-inflammatory state, with deposition of IgA and C3 complexes in the walls of the small vessels. The clinical criteria for diagnosis, as defined in 2006 by the European League Against Rheumatism and the Pediatric Rheumatology European Society, requires palpable purpura along with one of the following: predominant $\operatorname{IgA}$ deposition on biopsy, arthritis or arthralgia, renal involvement (hematuria/proteinuria), or abdominal pain. Renal involvement occurs in the form of glomerulonephritis, which is exhibited in approximately $30-50 \%$ of the patients, and is the principal cause of morbidity and mortality in the patients. HSP is a clinical diagnosis but tests may be conducted to detect any associated complications of the disease. The management of HSP focuses on a bimodal strategy of supportive care and management of complications of the disease. The supportive care includes hydration and analgesia. Corticosteroid or immunosuppressant may be added to reduce the extent of inflammatory tissue damage in severe cases.
\end{abstract}

Index Terms- Henoch Schönlein Purpura, HSP, Palpable Purpura, Small Vessel Vasculitis.

\section{INTRODUCTION}

Henoch-Schönlein purpura (HSP) is an acute IgA-mediated multisystem disorder, characterized by the involvement of vessels of the skin, gastrointestinal tract, kidneys, joints, and rarely the lungs and central nervous system [1]. It has been stated that the highest incidence exists in the age group of four-eight years, with up to $90 \%$ of the cases occurring prior to age of 10 years [2]. The annual incidence varies geographically from 6.2 to 70.3 per 100,000 population in the pediatric group with a male predominance (Male: Female $=1.2: 1.0$ ) [3]. Vasculitis disorders are classified as small, medium and large vessel vasculitis depending on the size of the blood vessel involved. HSP is typically characterized as a small vessel vasculitis disorder [1].

\section{CASE FINDINGS}

A 7-year-old male, resident of Pune, presented to the hospital with complaints of painful swelling of his right elbow and left knee joint for a week. This was followed by a progressive rash which initially involving the buttocks and then the lower limbs. Rash was associated with intermittent undocumented fever spikes. Patient also reported moderate grade, intermittent, non-progressive, diffuse pain over the abdomen. Patient denies any hematuria, oliguria, malena, vomiting, testicular or chest pain and hemoptysis. On Examination, the left knee joint was erythematous, mildly swollen and tender with restricted movements and there was also mild swelling in right elbow joint. Skin examination showed multiple purplish, palpable purpuric lesions, involving the buttocks and lower limbs. The rash involved both the flexor and extensor aspects of the thigh, popliteal fossa, and medial aspect of the leg (Figure 1A and B: Palpable purpura and Figure 2: Pustular lesion). The remainder of physical examination was completely normal. The differentials considered are as described in table $\mathbf{I}$.

The laboratory investigations commenced with a complete blood count (CBC) which showed, normal red cell and platelet count with mild leukocytosis protein ( $\mathrm{Hb}-12.1 \mathrm{~g} / \mathrm{dL}$, TLC- $11100 / \mathrm{mm} 3$ and Platelet count-3.84/mm3). The protein on spot urine test was found to be $10.28 \mathrm{mg} / \mathrm{dL}$. The blood urea nitrogen (BUN) and creatinine levels were found to be within normal limits. Renal biopsy was not indicated due to normal renal function tests. Ultrasonography (USG) of the abdomen and pelvis was conducted to investigate the cause of abdominal pain and demonstrated no abnormal findings. X-ray of right elbow and left knee showed minimal joint effusion and soft tissue swelling. Skin biopsy with indirect immunofluorescence showed deposition of IgM in the skin. The investigations have been 
described in table II. Finally, using the EuLAR and PReS criteria, the diagnosis of HSP was made. According to this criterion, the patient suffers from HSP, due to presence of palpable purpura and arthritis/arthralgia and diffuse abdominal pain [4].

Over the hospital course, the child was hemodynamically stable and was maintained on acetaminophen and nonsteroidal antiinflammatory drugs. His elbow and knee swelling subsided gradually. He was discharged on oral analgesic Ibugesic plus, which contains $200 \mathrm{mg}$ of ibuprofen and $325 \mathrm{mg}$ of acetaminophen, to be taken twice daily with a plan to follow up on an out-patient basis.

\section{Table I: Differential Diagnosis for HSP}

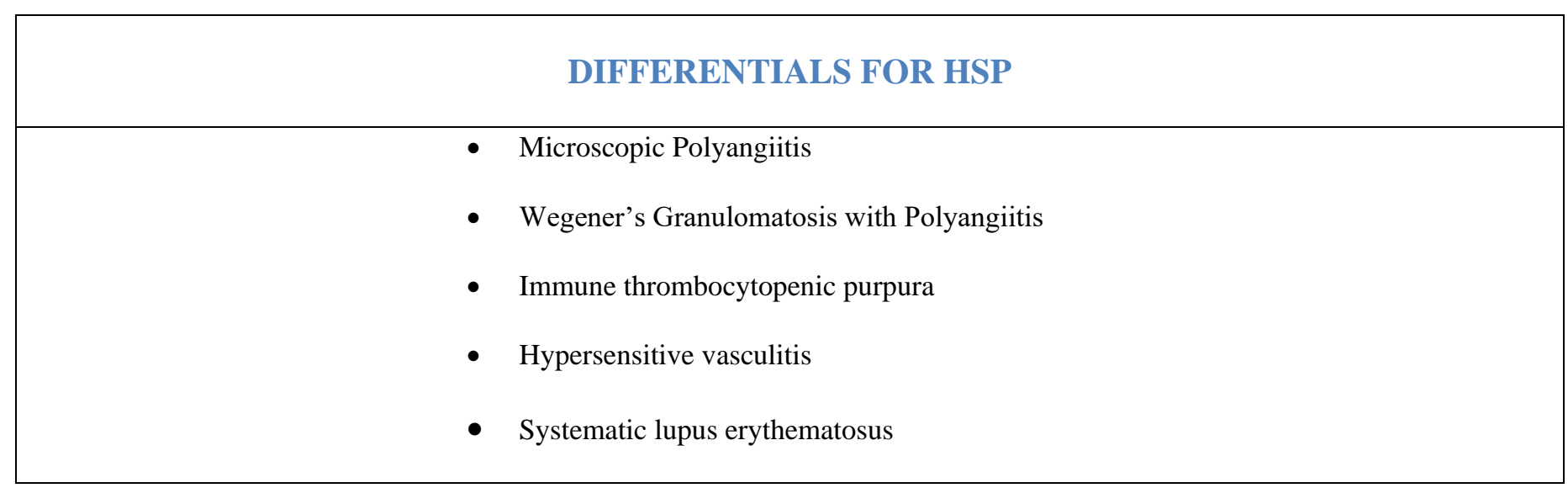

Table II: Investigations for diagnosis of complications of HSP

\begin{tabular}{|l|l|}
\hline \multicolumn{1}{|c|}{ INVESTIGATION } & \multicolumn{1}{c|}{ REPORTED FINDINGS } \\
\hline X ray Right Elbow Joint & Minimal soft tissue swelling seen \\
\hline $\begin{array}{l}\text { Ultrasound Abdomen and } \\
\text { Pelvis }\end{array}$ & No significant abnormality detected \\
\hline CBC & Hb: $12.1 \mathrm{~g} / \mathrm{dl}$ TLC: $11100 \mathrm{~N}: 64, \mathrm{~L}: 29$ PLT: 3.84 lakh \\
\hline Urine analysis & No red cells, casts. 1 +Protein present \\
\hline Creatinine and BUN & $0.4 \mathrm{mg} / \mathrm{dl}$ and $18 \mathrm{mg} / \mathrm{dl}$ \\
\hline Protein on Urine spot test & $15.64 \mathrm{mg} / \mathrm{dl}$ \\
\hline Renal Biopsy & Not performed \\
\hline Skin Biopsy & IgM deposition in the skin \\
\hline
\end{tabular}



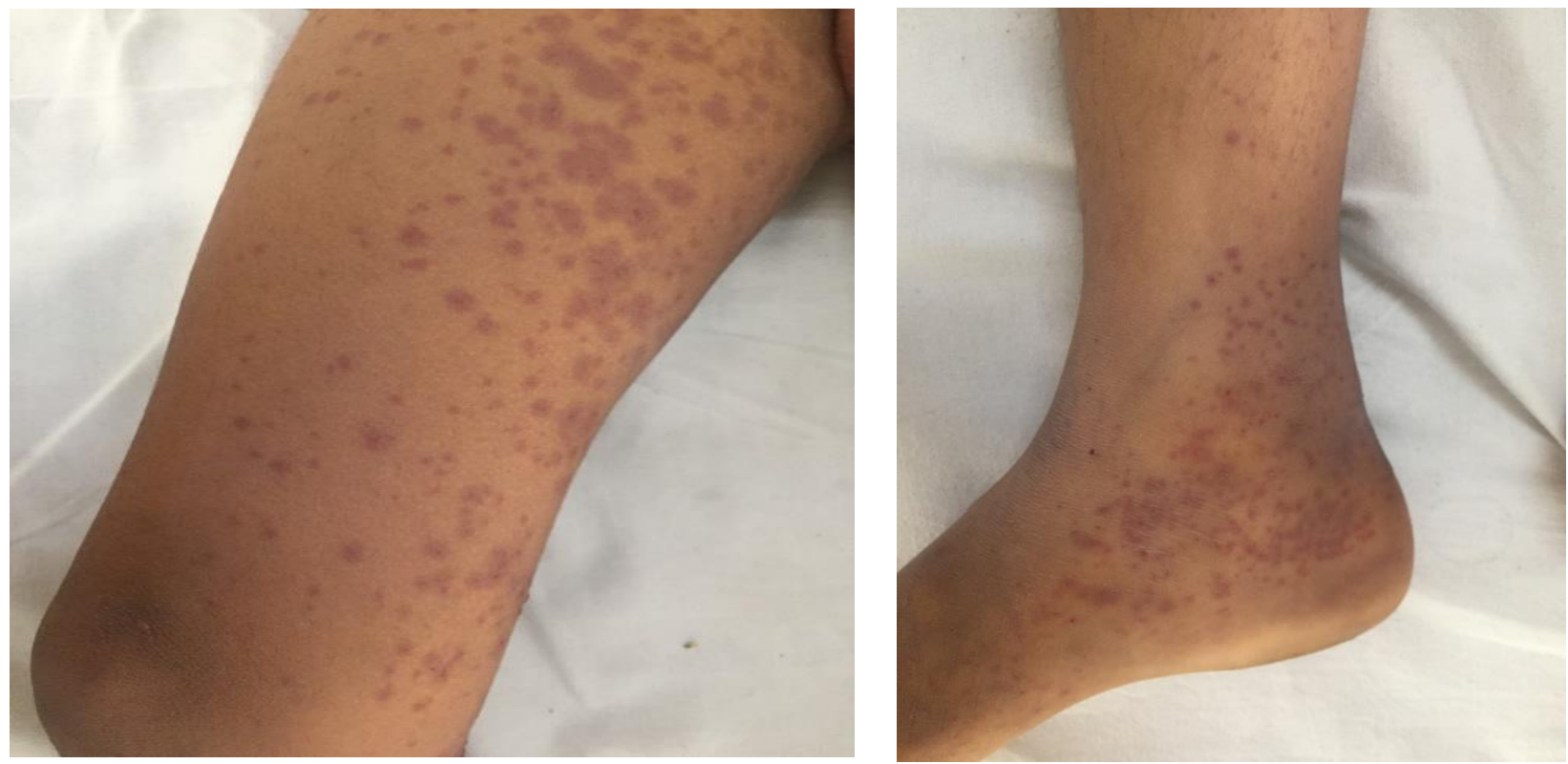

Figure 1 A and B: Palpable Purpura of HSP over the lower limbs

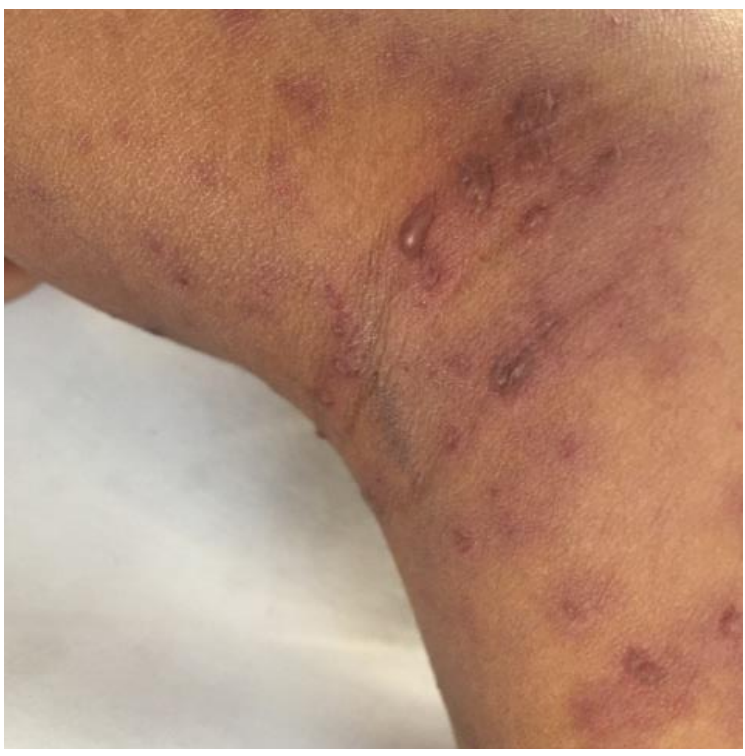

\section{Figure II: Pustular lesions of HSP}

\section{REVIEW OF LITERATURE}

Henoch- Schönlein Purpura is a childhood small vessel vasculitis, characterized by non-thrombocytopenic palpable purpura, arthritis or arthralgias, gastrointestinal and renal involvement [4,5]. In 1801 Dr. William Heberden, physician in London, described the first case of HSP in a 5-year old boy who reported severe painful inflammation of the joints, acute abdomen, hematuria and a purpuric rash over his leg. The young patient experienced all four hallmarks of HSP: arthritis, gastrointestinal involvement, renal inflammation and purpura. Johann Schönlein (1837) and Edouard Henoch (1874) reported some additional cases years after Heberden. They observed 
that the disorder often followed upper respiratory tract infections and was not always self-limited, sometimes progressing to serious renal involvement [6].

The pathogenesis of HSP has not been clearly elucidated as of yet. However, some potential triggers have been identified, ranging from basic allergens such as insect bites to infections with Epstein Barr virus, adenoviruses, Mycoplasma, Legionella, even vaccines such as typhoid, measles, yellow fever and medications such as beta- lactam antibiotics, erythromycin, quinine or quinidine. The pathogenesis is believed to include a dysregulated immune response, that results in a pro-inflammatory state, with deposition of IgA and C3 complexes in the walls of the small vessels [7-9].

The clinical criteria for diagnosis, as defined in 2006 by the European League Against Rheumatism and the Pediatric Rheumatology European Society, requires palpable purpura along with one of the following: predominant IgA deposition on biopsy, arthritis or arthralgia, renal involvement (hematuria/proteinuria), or abdominal pain [4]. In comparison to adult patients, the prevalence rates of joint and gastrointestinal (GI) involvement were higher in pediatric HSP patients in some studies [10,11]. Renal involvement occurs in the form of glomerulonephritis, which is exhibited in approximately 30-50\% of the patients, and is the principal cause of morbidity and mortality in the patients [12-14]. According to the metanalysis conducted by Chan et al., children older than 10 years were more likely to have renal involvement [15]. Although HSP nephritis usually occurs within 4-6 weeks of the preliminary presentation, it might also be a delayed complication, so a 6-month follow-up with urinary evaluations is recommended after the onset of HSP $[16,17]$. disease may sometimes have an atypical presentation such as seizures, limb weakness, focal deficits, painful menstruation, hematemesis, malena, subcutaneous edema and orchitis [18]. Some studies report an association of HSP with Kawasaki's disease (KD) and dilated coronaries. Vedagiriswaran et al. described a five-year-old patient, who presented with concurrent HSP and KD, including dilated coronary arteries [19]. Similarly, Heldrich et al. discussed a three-year-old who presented with KD, developed Hemolytic Uremic Syndrome on day three, and then HSP by second week [20]. Furthermore, HSP patients may experience some complications such as Berger's disease, intussception, orchitis, Gullian Barre Syndrome and Hypertension [18].

HSP is a clinical diagnosis but tests may be conducted to detect any associated complications of the disease [21]. These include urine routine to detect blood or proteins in urine and serum IgA levels. Serum BUN and creatinine levels should be done to assess renal injury. Renal biopsy follows the renal function tests when they indicate possible renal injury. Renal biopsy demonstrates proliferative glomerulonephritis with IgA deposition in the mesangium of the kidney. Renal biopsy is a definitive, but invasive way to diagnose renal involvement, yet it is not routinely obtained. It would be advantageous to determine a noninvasive measure to predict renal involvement in HSP patients [15]. Indirect immunofluorescence may be conducted for IgA, IgM and C3 deposits, while USG abdomen-pelvis to detect concurrent intussusception and to further investigate the cause of abdominal pain. Skin biopsy from the involved sites will show leukocytoclastic vasculitis with IgA or IgM or complement deposits [22]. According to a cross-sectional study by Ataeepour et al., IgM deposition in the skin is a marker of joint involvement and does not indicate any associated renal disease [22]. However, the same study also shows that deposition of C3 in the skin does indicate renal involvement, which is parallel to the results of another retrospective study conducted by Johnson et al [22,23].

The management of HSP focuses on a bimodal strategy of supportive care and management of complications of the disease. The supportive care encompasses adequate hydration and analgesia. For mild pain, a regular paracetamol with or without a short course of NSAIDs such as ibuprofen $(10 \mathrm{mg} / \mathrm{kg}$ TDS) or naproxen $(10 \mathrm{mg} / \mathrm{kg}$ BD) can be used if not otherwise contraindicated. However, for moderate to severe pain necessitates addition of glucocorticoids, which have been shown to reduce the duration of abdominal and joint pain, but do not impact long-term renal complications. Oral prednisolone $1-2 \mathrm{mg} / \mathrm{kg} / \mathrm{day}$ (maximum $60 \mathrm{mg} / \mathrm{day}$ ) or IV methylprednisolone 0.8-1.6 mg/kg/day (maximum 1g/day) can be used while symptoms persist [3,5]. Immunosuppressive drugs (cyclophosphamide, azathioprine, cyclosporine A, and mycophenolate mofetil) in combination with high-dose IV pulse steroids are recommended if there is no benefit from steroids alone [24-26]. According to the Kidney Disease Improving Global Outcomes (KDIGO) guidelines, ACE inhibitors or Angiotensin receptor blockers (ARB) should be used to counteract and reduce proteinuria or nephrotic syndrome associated with IgA deposition in the mesangium [27]. Plasmapheresis or intravenous immunoglobulin therapy used for cases refractory to steroids and immunosuppressive drugs. Prognosis depends on organ involvement [24-26]. Renal involvement is associated with poor prognosis. Adults have worse prognosis as compared to children [15].

\section{CONCLUSION}

HSP is an acute IgA- mediated small vessel vasculitis with involvement of skin, joints, kidneys or bowel. The disorder can be diagnosed clinically by history and physical examination. However, investigate may be necessitated to evaluate complications of the disease. The treatment is mainly supportive care with use of analgesic and anti-inflammatory agents. Steroids or immunosuppressive agents may be required for refractory cases. 


\section{REFERENCES}

1) Henoch EH. Uber eineigenthe Form von Purpura. Berl Klin Wochenschr. 1974;11:641-3.

2) Kamath N, Rao S. Henoch-Schonlein purpura: An update. Indian Journal of Rheumatology. 2012 May 1;7(1):92-8.

3) Sohagia AB, Gunturu SG, Tong TR, Hertan HI. Henoch-Schonlein purpura-a case report and review of the literature. Gastroenterology research and practice. 2010 Oct;2010.

4) Ozen S, Ruperto N, Dillon MJ, Bagga A, Barron K, Davin JC, Kawasaki T, Lindsley C, Petty RE, Prieur AM, Ravelli A. EULAR/PReS endorsed consensus criteria for the classification of childhood vasculitides. Annals of the rheumatic diseases. 2006 Jul $1 ; 65(7): 936-41$.

5) Bluman J, Goldman RD. Henoch-Schönlein purpura in children: limited benefit of corticosteroids. Canadian Family Physician. 2014 Nov 1;60(11):1007-10.

6) Roache-Robinson P, Hotwagner DT. Henoch Schonlein Purpura (Anaphylactoid Purpura, HSP).

7) Petty RE, Lindsley CB, et al. Cassidys textbook of pediatric rheumatology. 7. Philadelphia: Elsevier; 2016

8) Tizard EJ, Hamilton-Ayres MJ. Henoch-Schönlein purpura. Archives of Disease in Childhood-Education and Practice. 2008 Feb $1 ; 93(1): 1-8$.

9) Aulsbury FT. Clinical update: Henoch-Schonlein purpura. Lancet. 2007;369(9566):976-8.

10) Belli AA, Dervis E. The correlation between cutaneous IgM deposition and renal involvement in adult patients with HenochSchönlein purpura. European Journal of Dermatology. 2014 Jan 1;24(1):81-4.

11) Poterucha TJ, Wetter DA, Gibson LE, Camilleri MJ, Lohse CM. Correlates of systemic disease in adult Henoch-Schönlein purpura: a retrospective study of direct immunofluorescence and skin lesion distribution in 87 patients at Mayo Clinic. Journal of the American Academy of Dermatology. 2012 Oct 1;67(4):612-6.

12) Kang Y, Park JS, Ha YJ, Kang MI, Park HJ, Lee SW, Lee SK, Park YB. Differences in clinical manifestations and outcomes between adult and child patients with Henoch-Schönlein purpura. Journal of Korean medical science. 2014 Feb 1;29(2):198-203.

13) Pillebout E, Thervet E, Hill G, Alberti C, Vanhille P, Nochy D. Henoch-Schönlein purpura in adults: outcome and prognostic factors. Journal of the American Society of Nephrology. 2002 May 1;13(5):1271-8..

14) Gupta A, Gupta A, Nada R, Minz RW, Suri D, Rawat A, Singh S. O27 Profile of Henoch Schonlein purpura (HSP) nephritis: 23 years of experience at a tertiary care centre in North India. Rheumatology. 2018 Apr 1;57(suppl_3):key075-209.

15) Chan H, Tang YL, Lv XH, Zhang GF, Wang M, Yang HP, Li Q. Risk factors associated with renal involvement in childhood henoch-schönlein purpura: a meta-analysis. PLoS One. 2016 Nov 30;11(11):e0167346.

16) Chen JY, Mao JH. Henoch-Schönlein purpura nephritis in children: incidence, pathogenesis and management. World Journal of Pediatrics. 2015 Feb 1;11(1):29-34.

17) Pohl M. Henoch-Schönlein purpura nephritis. Pediatric Nephrology. 2015 Feb 1;30(2):245-52.

18) Chimenz R. Introduction to the special issue:" Focus on pediatric nephrology". Journal of biological regulators and homeostatic agents. 2019;33(5 Suppl. 1)

19) Vedagiriswaran VV, Amperayani S, Ramamoorthy RK, Ranjith MS. A case of Henoch-Schönlein Purpura with Kawasaki disease. The Indian Journal of Pediatrics. 2014 Apr 1;81(4):408-9.

20) Heldrich FJ, Jodorkovsky RA, Lake AM, Parnes CA. Kawasaki syndrome: HUS and HSP complicating its course and management. Maryland medical journal (Baltimore, Md.: 1985). 1987 Sep;36(9):764.

21) Yang YH, Yu HH, Chiang BL. The diagnosis and classification of Henoch-Schönlein purpura: an updated review. Autoimmunity reviews. 2014 Apr 1;13(4-5):355-8.

22) Ataeepour M, Monajemzadeh M, Sadeghi P, Ziaee V. Direct Immunofluorescence Results of the Skin Biopsy and Frequency of Systemic Involvement in Children with Henoch-Schonlein Purpura. Fetal and pediatric pathology. 2019 Mar 4;38(2):121-6.

23) Johnson EF, Lehman JS, Wetter DA, Lohse CM, Tollefson MM. Henoch-Schönlein purpura and systemic disease in children: retrospective study of clinical findings, histopathology and direct immunofluorescence in 34 paediatric patients. British Journal of Dermatology. 2015 May;172(5):1358-63.

24) Flynn JT, Smoyer WE, Bunchman TE, Kershaw DB, Sedman AB. Treatment of Henoch-Schönlein Purpura glomerulonephritis in children with high-dose corticosteroids plus oral cyclophosphamide. American journal of nephrology. 2001;21(2):128-33.

25) Kawasaki Y, Suyama K, Hashimoto K, Hosoya M. Methylprednisolone pulse plus mizoribine in children with HenochSchoenlein purpura nephritis. Clinical rheumatology. 2011 Apr 1;30(4):529-35.

26) Kawasaki Y, Suzuki J, Suzuki H. Efficacy of methylprednisolone and urokinase pulse therapy combined with or without cyclophosphamide in severe Henoch-Schoenlein nephritis: a clinical and histopathological study. Nephrology Dialysis Transplantation. 2004 Apr 1;19(4):858-64.

27) Chapter 11: Henoch-Schönlein purpura nephritis. Kidney Int Suppl (2011) 2012;2:218-220. 


\section{AUTHORS}

First Author - Dr. Zubin A. Mahajan, M.B.B.S., Bharati Vidyapeeth University Medical College, Pune, Maharashtra, India, mahajanzubin56@gmail.com

Second Author - Dr. Sameera R. Mehta, Junior Resident, Department of Pathology, Smt. Kashibai Navale Medical College \& General Hospital, Pune, Maharashtra, India, sameeramehta@ hotmail.com

Third Author - Dr. Raman Singh, M.B.B.S., Bharati Vidyapeeth University Medical College, Pune, Maharashtra, India, proframan@hotmail.com

Correspondence Author - Dr. Zubin A. Mahajan, mahajanzubin56@gmail.com, +91-9011666309 